\section{Estudo \\ Ecidebate}

em Cestão

Plamejamento

\title{
OS DIFERENTES CLUSTERS DE CONSUMIDORES DO CAFÉ BRASILEIRO: ESTUDO SOBRE AS ATITUDES, CRENÇAS E MARCA BRASIL
}

\author{
Liliane Antunes Rohde ${ }^{1}$, Ana Carina Castagna ${ }^{2}$
}

\begin{abstract}
Resumo: O Brasil configura-se como o maior produtor e exportador de café, apesar dessa posiçáo, o sistema agroindustrial do café é voltado para a produção e comercialização do grão in natura, não sendo tão reconhecido, mundial e nacionalmente, como um produtor de cafés de qualidade. Assim, o objetivo deste artigo é analisar o consumo de cafés junto aos consumidores brasileiros, com base nos elementos formadores das atitudes sobre o próprio café brasileiro, para propor a criação da marca cafés do Brasil de "dentro para fora". Constatam-se, na etapa qualitativa, a partir das entrevistas em profundidade realizadas com especialistas e consumidores de café, os julgamentos e as emoçóes envolvidos no consumo da bebida. Na fase quantitativa abordam-se as atitudes relativas ao consumo de cafés brasileiros e assim, a partir da cluster analyses compreende-se três diferentes tipos consumidores com relação aos cafés nacionais. Entre os resultados, destacam-se a crença dos consumidores de que é mais difícil encontrar cafés de boa qualidade do Brasil no próprio país do que no exterior e a presença de atitudes predominantemente positivas, porém racionais, o que pode indicar a falta de construção de marca dos cafés do Brasil no mercado nacional.
\end{abstract}

Palavras-chave: Marcas. Cafeicultura. Comportamento do consumidor. Atitudes. Imagem.

\section{THE DIFFERENT CLUSTERS OF BRAZILIAN COFFEE CONSUMERS: A STUDY ON ATTITUDES, BELIEFS AND BRAZIL BRAND}

\begin{abstract}
Brazil appears as the largest producer and exporter of coffee in the world, despite this position, the Brazilian coffee agribusiness system is focused only on the production and commercialization of in natura grain, however, it is not, worldwide and nationally, recognized as a producer of premium quality. Thus, the objective of this paper is to analyze the consumption of coffee by Brazilian consumers, based on the formative elements of attitudes about Brazilian coffee itself, in order to propose the creation of the Brazilian Coffee brand. The judgments and the emotions involved in the consumption of the beverage can be seen in the qualitative stage, from the in-depth interviews conducted with coffee specialists and consumers. In the quantitative phase, the
\end{abstract}

1 Mestre em Administração de Empresas pela UFRGS. Professora dos cursos de graduação da ESPM/Sul. Consultora de Empresas.

2 Graduada em Relaçôes Internacionais pela ESPM-Sul e graduanda em Administração pela mesma instituição. 
attitudes related to the consumption of Brazilian coffee are approached, and thus, from the cluster analyzes, we found out three different types of consumers regarding to national coffee. Among the results, we point out the consumers' belief that it is more difficult to find good quality coffee from Brazil in their own country than abroad, and the presence of predominantly positive however rational attitudes, which may indicate a lack of brand building of Brazilian coffee in the national marke.

Keywords: Trademarks. Coffee. Consumer behavior. Attitudes. Image.

\section{INTRODUÇÁO}

O Brasil caracteriza-se por ser o maior produtor e exportador de cafés do mundo. No entanto, o sistema agroindustrial do café no país é voltado para a produçáo e comercialização de quantidade, não sendo reconhecido, mundial e nacionalmente, como um produtor de cafés de qualidade, recebendo, assim, preços mais baixos do que a média. Consequentemente, a maioria das exportaçóes brasileiras no setor compreende a venda de produtos in natura: "O Brasil faz o hard e deixa o soft para ser feito fora" (NEVES, 2011, p. 50). Entretanto, desde a década de 1990 ocorre uma onda de mudança no sistema agroindustrial de café brasileiro no âmbito do aumento da produção de cafés com maior qualidade, denominados cafés especiais. Dois motivos se tornam importantes para a análise dessa mudança. Preliminarmente, na década de 1990, ocorreu a desregulamentação do mercado cafeeiro devido ao fim do Instituto Brasileiro do Café, o que desencadeou a desvalorização da commodity (LEÃO; PAULA, 2010). O segundo motivo está associado ao aumento do poder de compra do consumidor brasileiro, também na década citada, o que gerou o aumento da exigência das pessoas perante os objetos de consumo. Esses dois fatores desenvolveram oportunidades e, ao mesmo tempo, desafios para a cafeicultura brasileira no que diz respeito ao nicho de cafés especiais.

Atualmente, o Brasil é o maior exportador do grão verde, ou seja, da commodity, a qual não passou por processos de agregação de valor ao produto. Todavia, o comércio de cafés industrializados, que passou por um processo de diferenciaçáo e de branding, sofre grandes barreiras protecionistas. Um dos principais motivos para o Brasil possuir facilidade de exportar grãos verdes, e não cafés torrados e moídos, está na indústria de reexportação, em que o café verde brasileiro é uma das maiores matérias-primas. Esse processo iniciase na exportação de grãos verdes e termina no comércio de cafés com valor agregado, porém, normalmente sem a denominação de origem brasileira (ORMOND; PAULA; CAFÉ FILHO, 1999). Visto à reexportação, a marca de origem do grão, em geral, não é reconhecida internacionalmente, assim, torna-se importante o estudo do desenvolvimento de marca dos cafés brasileiros perante o mercado nacional. Diante do desafio de entrada de cafés brasileiros industrializados no mercado internacional, este estudo propóe a construçáo da marca de cafés brasileiros "de dentro para fora", visando atingir primeiramente o consumidor local.

A exigência do consumidor brasileiro é cada vez mais representativa, e para que os produtos possam sobressair-se no mercado, torna-se essencial o desenvolvimento de marcas que sejam capazes de cativar estes consumidores. Nesse sentido, o papel do estudo das atitudes e da temática das marcas torna-se estratégico nesse cenário competitivo, considerando-se o que Batey (2010, p. 13) afirma: "Embora as empresas criem identidades de marca, o 
significado da marca é criado pelas pessoas". Dessa forma, buscando aliar o processo de descomoditização com a estratégia de branding, evidencia-se a necessidade da construção da marca "de dentro para fora", estratégia que deve ser iniciada pelo conhecimento do consumidor local (AAKER; JOACHIMSTHALER, 2007). Ou seja, desenvolver uma identidade e imagem dos cafés brasileiros nacionalmente e, após, exportá-las para outras culturas, pois a valorização do produto nacional pelos brasileiros é um passo importante no processo de internacionalização da marca.

O desenvolvimento desse processo necessita diferenciar e agregar valor ao agronegócio, fatores importantes para a busca da liderança e conquista do mercado. Considerando o cenário descrito, neste artigo analisam-se as atitudes, crenças e sentimentos dos consumidores a respeito dos cafés brasileiros, levando em consideração a imagem da cafeicultura brasileira e a Marca Brasil. Portanto, percebe-se que o estudo das atitudes dos consumidores brasileiros perante os cafés nacionais torna-se fundamental para a descoberta da imagem e da identidade do produto brasileiro. Assim, o questionamento que se faz é: Como são os perfis de consumidores do café brasileiro a partir de suas atitudes? Logo, analisar o consumo de cafés nacionais junto aos consumidores brasileiros, com base nos elementos formadores das atitudes, é o objetivo geral que norteia este estudo. Como objetivos específicos apresentam-se: identificar as associações dos consumidores brasileiros em relação ao café made in Brazil; analisar as crenças desses consumidores; e selecionar os aspectos cognitivos e hedônicos referente às atitudes dos consumidores.

\section{REVISÃO DA LITERATURA}

Neste tópico, abordam-se os principais conceitos sobre os quais se discorre neste artigo: Atitudes, Marcas e Consumo. Por se tratar de um recorte de um estudo mais amplo, selecionam-se, neste capítulo, as principais teorias e autores que ilustram os resultados encontrados nas entrevistas em profundidade e questionários.

\section{ATITUDES}

A atitude é considerada uma avaliação geral realizada pelos seres humanos. Atualmente, compreender as atitudes é uma das ações mais notáveis na pesquisa do consumidor e na psicologia social (PETER; OLSON, 2009; MOWEN; MINOR, 2003). Karsaklian (2000) destaca que as atitudes demonstram as disposições ou intençóes das pessoas em relação a um objeto e são um dos fatores mais importantes para a explicação do comportamento de compra. Configura-se como uma união de processos motivacionais e emocionais na mente dos consumidores, processos estes que também incluem avaliaçóes cognitivas sobre produtos, marcas e serviços. Assim, a atitude conceitualiza-se como uma predisposição que as pessoas possuem e que as guia para reagirem de forma favorável ou desfavorável em relação a um produto ou serviço (MOWEN; MINOR, 2003; HAWKINS; MOTHERSBAUGH; BEST, 2007).

As atitudes são criadas a partir de respostas afetivas, pelo sistema afetivo, ou por julgamentos e avaliaçóes desenvolvidas através do sistema cognitivo. No âmbito do consumo hedônico, Batey (2010) considera que as atitudes são as respostas afetivas das pessoas em relação a uma marca. O elemento emocional, ou irracional, da atitude é o mais 
difícil de se analisar no comportamento de consumo, diz o autor: "Quando a atitude em relação a uma marca é determinada em larga escala pelos elementos funcionais e racionais, os consumidores têm mais chance de verbalizar os motivos e atitudes que os levaram aquela escolha" (BATEY, 2010, p. 204). Por outro lado, as emoçóes das marcas são os elementos que mais marcam e motivam os consumidores ao ato da compra, tornando-se fatores competitivos em relação aos concorrentes.

$\mathrm{Na}$ literatura existe a concordância de que as atitudes são aprendidas através das experiências de consumo, não apenas limitadas ao ato da compra, mas também à exposição de propagandas e opinióes de grupos de influência. Nesse sentido, a atitude náo é sinônimo de comportamento, mas pode resultar em um comportamento, refletindo, assim, as avaliaçóes que podem motivar os consumidores à decisão final ou até à fidelidade. Dessa forma, produtos que recebem avaliaçôes positivas possuem maior tendência de serem adquiridos. Entretanto, em uma conotaçáo negativa, as atitudes também influenciam o distanciamento do produto. Por outro lado, a consistência da atitude em relação ao comportamento poderá ser afetada de acordo com a situação de compra (escolha pela economia) e através das mudanças de atitude ao longo do tempo. Nesse sentido, nota-se que o comportamento de compra é influenciado por variáveis externas, sendo que nem sempre o produto com mais atitudes positivas será comprado (SCHIFFMAN; KANUK, 2009; SOLOMON, 2002).

Hawkins, Mothersbaugh e Best (2007) acreditam que existem três componentes formadores da atitude: o afetivo, manifestado por emoçóes ou sentimentos; o cognitivo, representado pelas crenças acerca do objeto; e o comportamental, que é manifestado por intençôes de compra. Para que a mente do consumidor possa formar esses componentes é necessário, segundo esses autores, a formação de estímulos iniciadores da atitude, os quais podem ser criados pela experiência do consumidor com propagandas, equipe de vendas, situaçōes e grupos de influência. Após o processo de formação desses componentes, a atitude é criada e armazenada na mente como uma orientação geral em relação a produtos, marcas e serviços específicos (HAWKINS; MOTHERSBAUGH; BEST, 2007).

As atitudes são desenvolvidas a partir das experiências vividas. Sendo assim, a formação de uma atitude é o resultado de uma aprendizagem obtida com a experiência. O desenvolvimento de atitudes pode ser estabelecido em dois momentos, antes da compra, a partir de crenças preestabelecidas ou depois do período da compra. No caso da formaçáo de atitudes após a compra, os consumidores podem adquirir produtos sem ter nenhuma avaliação ou envolvimento a respeito do mesmo, efetuando uma compra experimental. Nesse caso, em específico, a atitude é desenvolvida apenas após a compra, sendo a escolha de compra baseada na situação e não em uma pré-avaliação (SCHIFFMAN; KANUK, 2009).

As predisposições possuem quatro funçóes que atuam na mente dos consumidores: utilitária, defesa do ego, conhecimento e valor. A função utilitária está relacionada aos benefícios de um produto e pode modificar atitudes a partir da demonstraçáo de que o objeto pode ser utilizado para um propósito, do qual antes as pessoas não tinham conhecimento. A função de defesa do ego relaciona-se às atitudes criadas em função de fugir da realidade ou de comprar um prazer momentâneo. A função do conhecimento auxilia a explicar a fidelidade do cliente, pois é utilizado para simplificar uma decisão de compra. Por fim, a função expressiva de valor está relacionada à identificação de um consumidor com 
determinado produto, marca, ou serviço, sendo a compra realizada para expressar os valores centrais de cada indivíduo (MOWEN; MINOR, 2003). Embora uma dessas funçóes se torne predominante durante a decisão de compra, as predisposiçóes podem atuar a partir de múltiplas funçóes (MOWEN; MINOR, 2003; HAWKINS; MOTHERSBAUGH; BEST, 2007).

É importante notar que, apesar de uma atitude estar relacionada a mais de uma função, uma ideia positiva ou negativa relacionada a um produto sempre está baseada em uma função central, a qual é a mais importante e dominante nas atitudes. Um consumidor, por exemplo, pode ter uma atitude positiva à marca Nespresso, pois a mesma satisfaz a função utilitária - sabor agradável -, e função defensiva do ego - estilo de vida. Entretanto, o motivo central que mais influencia a atitude positiva é a função defensiva do ego, pois consumir cafés Nespresso projeta um estilo de vida ideal (SOLOMON, 2002). No entanto, a maioria das pessoas valoriza mais a função utilitária do café do que a função expressiva de valor ou defensiva do ego (SOLOMON, 2002). No próximo tópico explora-se a temática das marcas e influência do made in.

\section{MARCAS E A INFLUÊNCIA DO MADE IN}

Os estudos relativos à percepção do consumidor sobre produtos fabricados em países estrangeiros têm-se tornado crescentes e possuem o objetivo de coletar a opinião dos consumidores e identificar se existe alguma influência da imagem do país de origem durante a decisão de compra. De fato, alguns consumidores dão preferência a produtos estrangeiros - sapatos italianos, vinhos chilenos e carros alemães. Sendo assim, as empresas de países que não possuem uma imagem tâo favorável diante de um setor específico, possuem maiores dificuldades ao se deparar com a concorrência internacional. Em muitos casos, o país de origem se torna uma garantia da qualidade do produto, e o consumo de produtos dele provenientes trazem benefícios simbólicos e emocionais para o consumidor, como a demonstração de um status social, além do orgulho nacional (ALMEIDA; DROUVOT, 2009).

Diversas pesquisas consideram que a informação sobre o país de origem gera um efeito significativo na avaliação dos produtos, oferecendo aos consumidores uma pista extrínseca sobre a qualidade dos mesmos (AGRAWAL; KAMAKURA, 1999; BILKEY; NESS, 1982; VAN ITTERSUM et al., 2003). Na literatura, o efeito país de origem está relacionado tanto com aspectos cognitivos quanto afetivos da decisão de compra. No aspecto cognitivo, a origem pode representar uma pista sobre a qualidade do produto (VERLEGH; STEENKAMP, 1999), assim como relacionar o produto com estereótipos da cultura e economia local, como a associação de que produtos de alta tecnologia possuem melhor qualidade quando fabricados por países desenvolvidos (VERLEGH; STEENKAMP, 1999). O efeito país de origem também está relacionado com aspectos afetivos dos julgamentos e das atitudes, onde a compra de produtos de determinados países é motivada por expressar autoimagens, estilos de vida e sentimentos como status e orgulho. Além disso, o efeito país de origem pode estar associado com uma ação de proteção ou boicote à economia dos países. Neste contexto, alguns consumidores acreditam ser moralmente adequado comprar produtos locais como forma de proteger a economia nacional, ou evitar produtos de países rivais no âmbito econômico ou militar (VERLEGH; STEENKAMP, 1999). 
Para Han (1989) os julgamentos baseados no país de origem geram um efeito halo que afeta as atitudes das pessoas sobre a marca. Neste contexto, Insch e McBride (2004) complementam que os consumidores podem passar por experiências negativas com um produto de determinada origem, e gerar um efeito halo negativo sobre todos os produtos provenientes do mesmo país. Desta forma, assim como o efeito país de origem pode gerar julgamentos positivos, ele também pode fazer com que os consumidores evitem ou boicotem a compra de produtos por não se identificarem com o país, ou por já terem passado por experiências negativas com produtos da mesma origem. Neste contexto, marcas de um mesmo país compartilham imagens e associaçóes em comum, que podem ser tanto positivas quanto negativas (SHIMP et al., 1993). Os cafés colombianos são um exemplo de efeito do país de origem (AGRAWALL; KAMAKURA, 1999), onde diversas marcas de café, com mesma origem, carregam uma imagem positiva devido ao posicionamento do país como um produtor de grãos de qualidade. O caso de sucesso do café colombiano tornou-se possível através da criação de marca, gerando associaçóes positivas que ligam o país à qualidade dos grãos.

O desenvolvimento de marcas existe há séculos e vem contemplando a história do marketing por ser o mecanismo de diferenciação mais utilizado pelas empresas ao redor do globo. Tavares (2008, p. 9) observa que "a marca é um dos ingredientes que as empresas utilizam em suas estratégias para diferenciar sua oferta. As empresas procuram serem as únicas a atender expectativas de grupos de consumidores específicos”. A criação de uma marca forte deve estar estabelecida em uma estratégia de longo prazo, a qual vise a proporcionar e comunicar benefícios funcionais, experienciais e simbólicos. "A marca é mais que um simples nome. O significado de uma marca resulta de esforços de pesquisa, inovação, comunicação e outros que, ao longo do tempo, vão sendo agregados ao processo de sua construção" (TAVARES, 2008, p. 17). A marca garante valorização e diferenciação aos produtos, que, antes, eram iguais aos olhos do mercado. Batey (2010, p. 27) afirma: "um produto físico se torna uma marca quando é acrescido de algo mais - imagens, símbolos, percepçóes, sentimentos". Caso não existissem marcas no mercado de automóveis, por exemplo, os produtos seriam dificilmente diferenciados, as pessoas comprariam carros apenas por benefícios funcionais. As marcas, portanto, se diferenciam a partir da proposta de oferecer benefícios, considerando não apenas aspectos externos do produto, mas também e, principalmente, fatores internos. Assim, a marca possui o objetivo de identificar e diferenciar objetos, sinalizando a origem do produto, qualidade, e suas vantagens perante os demais concorrentes (AAKER, 1998; AAKER; JOACHIMISTHALER, 2007; BATEY, 2010; TAVARES, 2008).

A criação de uma marca deve acarretar o desenvolvimento de um valor para os consumidores, criando ativos intangíveis que podem valer mais do que todo o capital fixo de uma empresa. Sendo assim, as marcas se tornam valiosas, pois identificam a origem do produto, atribuem responsabilidade à fabricação e ao fabricante, auxiliam a reduzir riscos, simplificam a decisão de compra, transmitem elementos simbólicos como a proteção da autoimagem e indicam qualidade. No entanto, para que a marca seja conceituada é necessário criar um diferencial, um posicionamento adequado que a identifique, tornando-a única aos olhos dos consumidores (AAKER, 1998). A construção deve ser orientada por três 
fatores norteadores: criar visibilidade no mercado; desenvolver um ponto de diferenciação capaz de fixar a marca na mente dos consumidores, com o intuito de gerar uma recordaçấo espontânea; desenvolver relacionamentos profundos com os consumidores, com o intuito de gerar fidelização. Criar associaçóes fortes diferencia a marca dos demais players, sendo este o segredo para a criação de marcas fortes, pois, em um mercado altamente competitivo, gerar valor ao cliente é essencial.

Assim, a criação de valor deve ser orientada para as necessidades e desejos do cliente. Portanto, conhecer o cliente se torna essencial para o desenvolvimento de pontos de diferenciação, pois a lealdade de marca depende das características únicas ofertadas ao mercado (AAKER; JOACHIMSTHALER, 2007). Quando se alcançam esses diferenciais, e entrega-se valor ao consumidor, surge a capacidade de gerar uma atitude positiva e, provavelmente, facilitar a decisão de compra das pessoas a favor da preferência pelos produtos da empresa.

O conceito de imagem da marca está relacionado aos pensamentos abstratos dos consumidores, os quais relacionam a marca a necessidades psicológicas e sociais. A imagem pode ser formada antes e depois da compra, não somente sendo o resultado de uma avaliação pós-consumo (KELLER; MACHADO, 2006). Enquanto a imagem da marca é voltada ao passado e reflete como a marca é atualmente percebida, a identidade centra-se no futuro e em como o estrategista deseja que a marca seja percebida pelos consumidores (AAKER, 2007). Entretanto, Batey (2010, p. 13) argumenta: "embora as empresas criem identidades de marca, o significado da marca é criado pelas pessoas". A partir dessa perspectiva, percebese que a estratégia de construção da identidade da marca auxilia a criação de associaçóes, porém, apenas os próprios consumidores vão selecionar e definir quais associaçóes realmente são válidas e percebidas nos produtos. A marca pode definir sua estratégia de posicionamento e identidade, mas sempre será o cliente que decidirá o que ela significa e, ao decidir, não costuma mudar (BATEY, 2010). Após tratar dos eixos teóricos desse artigo, passa-se a trabalhar e descrever o método que o norteia.

\section{MÉTODO}

A presente pesquisa possui caráter exploratório e descritivo, onde busca-se construir um conhecimento sobre o objeto de estudo e também retratar o fenômeno de consumo de cafés no Brasil, descobrindo comportamentos e características desse mercado. No presente artigo, que se constitui em um recorte de uma pesquisa mais ampla, realiza-se, em sua primeira etapa, um estudo exploratório com vertente qualitativa. Após, para a concretização da pesquisa descritiva, faz-se o uso da vertente quantitativa.

A coleta de dados qualitativos foi feita através de entrevistas em profundidade, conduzidas pelas autoras, com consumidores de cafés especiais e especialistas. Entende-se que a escolha da técnica é adequada ao presente estudo, pois garante melhor compreensão acerca das atitudes dos consumidores selecionados e sua posição frente aos cafés nacionais e internacionais, além da opiniáo dos experts sobre a atual conjuntura da cafeicultura brasileira. A escolha dos consumidores entrevistados aconteceu através da amostragem por conveniência, na qual as unidades foram selecionadas através do critério de consumir café todo o dia ou várias vezes ao dia. Os especialistas participantes foram abordados através 
da técnica de bola de neve onde as pessoas selecionadas indicaram outros profissionais que possuem expertise em agronegócios e na cadeia do café. Nesse momento não foi levado em consideração a localização geográfica destes especialistas, e sim, sua expertise reconhecida no setor em estudo.

$\mathrm{Na}$ etapa qualitativa, os consumidores entrevistados se localizam na cidade de Porto Alegre, onde o consumo da bebida possui grande aderência entre as famílias e é uma das dez cidades que mais consome a bebida no país (ABIC, 2010). O objetivo da realização das entrevistas antes do questionário foi o de demonstrar a opiniáo dos consumidores e experts sobre a situação dos cafés brasileiros no mercado nacional e a atitude dos consumidores perante a escolha da marca de café a ser consumida. Para essa etapa escolheu-se entrevistados a partir da segmentação por índice de utilização, como heavy users. Essa segmentação da amostra considera que o consumo de café ou é feito todo o dia, ou várias vezes ao dia. $\mathrm{O}$ Quadro 1 apresenta a unidade de estudo selecionada para as entrevistas em profundidade, separada em consumidores e especialistas.

Quadro 1 - Descrição da Unidade de Estudo

\begin{tabular}{|c|c|c|c|c|c|}
\hline \multicolumn{6}{|c|}{ Apreciadores de cafés especiais } \\
\hline & Gênero & Idade & Escolaridade & Ocupação & Cidade de Residência \\
\hline 01 & $\mathrm{~F}$ & 23 & Superior Incompleto & Estudante & Porto Alegre, RS \\
\hline 02 & $\mathrm{~F}$ & 22 & Superior Incompleto & Estudante & Porto Alegre, RS \\
\hline 03 & M & 30 & Superior Completo & Engenheiro Civil & Porto Alegre, RS \\
\hline 04 & $\mathrm{~F}$ & 52 & Superior Completo & Fisioterapeuta & Porto Alegre, RS \\
\hline 05 & M & 21 & Superior Incompleto & Assistente Comercial & Porto Alegre, RS \\
\hline \multicolumn{6}{|c|}{ Experts } \\
\hline 01 & $\mathrm{~F}$ & 46 & $\begin{array}{l}\text { Doutora em } \\
\text { Agronegócios }\end{array}$ & $\begin{array}{c}\text { Gerente de Marketing de } \\
\text { Cooperativa }\end{array}$ & Rio Verde, GO \\
\hline 02 & M & 40 & Engenheiro Químico & $\begin{array}{l}\text { Consultor em Marketing } \\
\text { e Qualidade de Cafés } \\
\text { Especiais. Cafeicultor. }\end{array}$ & São Paulo, SP \\
\hline
\end{tabular}

Fonte: Elaborado pela Autora, 2015.

Para interpretar os dados coletados nas entrevistas adotou-se a análise de conteúdo. Para Bardin (2004), esse método de análise possui os objetivos de superar a incerteza da informação e gerar o enriquecimento da leitura, pois se descobrem conteúdos que confirmam a mensagem subscrita, gerando maior compreensão do conteúdo obtido. Assim, a análise é feita a partir do uso de procedimentos sistemáticos, desenvolvendo operaçóes de comparação e de classificação da mensagem. Para tanto, foram definidas categorias a priori relacionadas aos objetivos propostos na presente pesquisa: (1) imagem; (2) atitudes; (3) sentimentos; (4) crenças. 
$\mathrm{Na}$ etapa descritiva foram aplicados questionários, sendo o método survey a ferramenta quantitativa de coleta de dados adotada. Optou-se por duas escalas específicas para o estudo das atitudes em torno dos alimentos: Attitude Toward the Act (Consuming a Food Item) (SHIV; FEDORIKHIM, 1999) e Attitude Toward the Product (Food) (ARIASBOLZMANN; CHAKRABORTY; MOWEN, 2000). A primeira escala, atitude em torno do ato, é destinada a avaliar a atitude das pessoas sobre o consumo de alimentos, e foi utilizada pelos autores no contexto específico do estudo de dois produtos: bolo de chocolate e salada de frutas. A segunda escala, atitude em torno do produto, foi adotada pelos autores para mensurar a predisposiçáo em relação a diversas marcas do setor de alimentos. Antes da realização do campo foi desenvolvido o pré-teste do questionário e sua aplicação ocorreu durante o período compreendido entre os dias 18 a 26 de maio de 2015, via ferramenta Google Forms.

No âmbito da técnica de amostragem foi selecionada a amostragem não probabilística por conveniência, em que a seleção das unidades de amostragem cabe normalmente ao pesquisador (MALHOTRA, 2005). Além dessa técnica, a survey foi distribuída entre o período mencionado, através do método bola de neve, o qual possibilitou a distribuição da pesquisa pela internet, por meio de Facebook e e-mail. E entre os formulários enviados, 202 foram respondidos e validados.

No que concerne ao perfil da amostra, a maioria dos entrevistados, $55,9 \%$, pertencem ao gênero feminino e $44,1 \%$ ao masculino. O perfil da amostra é majoritariamente composto por mulheres devido ao fato da utilização das redes de network como base inicial para a distribuição do questionário aplicado. As pessoas selecionadas formaram a unidade amostral primária, que, a partir das indicaçóes de amigos e conhecidos, deram origem a todas as respostas coletadas. A metodologia bola de neve é uma técnica tipicamente utilizada em pesquisas sociais, e se torna adequada ao presente estudo pois a partir dela tornou-se possível a participação de consumidores de café que estão fora do alcance da rede de network dos pesquisadores, como a amostra em outros estados (ALBUQUERQUE, 2009). Além deste fator, é importante mencionar que, dentre todos os householders que compóem a unidade domiciliar, as mulheres ainda são as principais responsáveis pela compra do café consumido em casa e são elas também as maiores responsáveis pela preparação do produto (ABIC, 2010). No âmbito da idade, $28 \%$ da amostra representa o intervalo de 19 a 24 anos e $26 \%$ a partir de 49 anos. No que concerne o nível de escolaridade, a maioria informou possuir Pós-Graduação ou Ensino Superior Incompleto, representando, respectivamente, $40 \%$ e $31 \%$ da amostra. Os dados coletados abrangem respostas de consumidores residentes em dez estados brasileiros: Rio Grande do Sul, Santa Catarina, Paraná, São Paulo, Minas Gerais, Mato Grosso do Sul, Pernambuco, Bahia, Distrito Federal e Rio de Janeiro, com a predominância de respondentes localizados no Sul e no Sudeste. Os locais pesquisados se mostram pertinentes devido ao elevado nível de penetração da bebida nas regiōes estudadas. Além disso, as regiōes com maior número de respondentes, Sul e Sudeste, registraram um percentual de $99 \%$ de declaraçáo de consumo de café em 2010, revelando a alta aderência da bebida nestes locais (ABIC, 2010).

Os resultados da etapa quantitativa foram analisados através da estatística descritiva multivariada, e a análise de argumentos conglomerados, denominada clusters analisys. $\mathrm{O}$ 
objetivo da análise de clusters é organizar os resultados estatísticos em estruturas semelhantes, classificando os dados em classes diferentes, agrupando-os por características semelhantes. Conforme Hair et al. (2005), essa ferramenta examina os resultados, a partir da perspectiva da formação de respondentes de acordo com as características dos mesmos, criando estatisticamente grupos amostrais, os quais diferenciam-se através da homogeneidade de respostas. Utiliza-se o software estatístico SPSS como um ferramental para a análise dos dados, o qual possibilita maior facilidade, auxiliando a organização de resultados. A partir da utilização do programa SPSS foram aplicadas as análises de clusters e o K-means. Formamse, portanto, três grupos de respondentes com o auxílio da função $K$-means, que separa os indivíduos a partir das classificaçóes discordantes, indiferentes ou concordantes.

Durante o desenvolvimento deste artigo certas limitações se tornaram perceptíveis. A primeira limitação é devido ao artigo constituir-se em um recorte de um estudo mais amplo. Além disso, destaca-se a limitação geográfica, pois não se expandiu a amostra, envolvendo consumidores de todos os estados brasileiros. No entanto, a amostra obtida é significativa e alcança os objetivos propostos no presente artigo. No próximo capítulo apresentam-se os resultados obtidos nas etapas exploratória e descritiva.

\section{ANÁLISE DOS RESULTADOS}

$\mathrm{Na}$ etapa qualitativa observou-se que os consumidores entrevistados ainda possuem julgamentos que reúnem sentimentos de desconfiança e crença de que os cafés brasileiros exportados são de melhor qualidade. Além disso, houve a identificação de uma crença comum entre os entrevistados, no que diz respeito à existência de dois tipos de cafés brasileiros, sendo separados em dois grupos: os de alta qualidade e os com mistura. Além desse fator, analisa-se a alta receptividade dos respondentes perante cafés internacionais, sobretudo cafés colombianos e cafeterias europeias e americanas. Entre os consumidores, apenas um se mostrou leal aos cafés brasileiros.

Nesse contexto, percebe-se que a valorização da venda de cafés industrializados brasileiros, e não apenas de commodities, deve ser desenvolvida com a criação da marca dos cafés locais "de dentro para fora", inicialmente envolvendo os consumidores nacionais e, após, os internacionais. Diante do significativo protecionismo internacional, no que envolve cafés industrializados, a atitude positiva dos brasileiros perante o próprio café é de grande importância para a indústria local (AAKER; JOACHIMSTHALER, 2007). Constata-se ainda que a marca de cafés brasileiros náo possui uma imagem concreta na mente dos consumidores, pois a sua identidade é inexistente devido à ausência de estratégia de marketing nesse setor. $\mathrm{O}$ consumidor $\mathrm{A}$ fala sobre essa percepção:

Eu morei fora e muita gente falava bem do café brasileiro e tipo aí...gostam e acham que o café brasileiro é comparado com os melhores cafés... Só que aqui é só café...a gente não enxerga e fala café brasileiro (risos). É só café. E tipo a gente vai lá no mercado e se comprarmos aqueles pacotóes, óbvio que ele vai ser diferente do que um café gourmet. Então é isso que nós brasileiros não percebemos. Que eles quando compram café brasileiro compram o gourmet e não compram o convencional. E a gente enxerga como apenas café convencional o café brasileiro (CONSUMIDOR A). 
Observa-se que existem diversas marcas brasileiras que vendem diferentes variedades e qualidades para um público variado, formando uma imagem ambígua do café nacional. Assim, a problemática dessa variedade está no fato de gerar um sentimento de desconfiança no consumidor. O efeito halo se mostrou presente na imagem de cafés especiais brasileiros, pois, à medida que existem fornecedores vendendo café com baixa qualidade no Brasil, os consumidores apreciadores de cafés especiais podem associar a baixa qualidade de um produto com todos os produtos da mesma origem. Por intermédio das entrevistas, percebese que todos os consumidores reconhecem a capacidade do Brasil em produzir cafés com ótima qualidade, e enxergam o país como um produtor tradicional no ramo. Entretanto, os mesmos também creem que a imagem do produto está sendo afetada pela associação direta do país vender ao público interno cafés com mistura e de baixa qualidade. Neste contexto, Insch e McBride (2004) complementam que os consumidores podem passar por experiências negativas com um produto de determinada origem, e gerar um efeito halo negativo sobre todos os produtos provenientes do mesmo país. Assim, a experiência com cafés de baixa qualidade acaba gerando um efeito negativo sobre todas as marcas de mesma origem. Este efeito pode ser reduzido a partir da divulgaçáo de certificaçóes de qualidade e investimento em branding com o intuito de alterar crenças negativas dos consumidores e aumentar a sua confiança no produto local.

$\mathrm{Na}$ etapa quantitativa, ao se analisar os resultados referentes às crenças: (1) O café brasileiro é pouco valorizado no Mundo; (2) O café brasileiro é pouco valorizado no Brasil, percebe-se que a amostra acredita que o produto é menos valorizado no próprio país do que no mercado mundial. Esse resultado pode estar relacionado ao fato de que o mercado estrangeiro, especialmente a Europa, foi o primeiro mercado consumidor dos cafés brasileiros, sendo assim, o produto era exportado procurando atender as preferências e necessidades internacionais (ESPECIALISTA B). Consequentemente, a produção de cafés brasileiros adquiriu um perfil exportador, sendo capaz de atender às diversas demandas mundiais. A evolução da qualidade e da agregação de valor no café ocorreu apenas a partir da década de 1990, quando a desregulamentação do mercado cafeeiro possibilitou uma mudança nos padróes de produção do café no país, abrindo caminho para a diferenciação. Nesse cenário, a indústria começou a perceber as necessidades dos consumidores brasileiros e a produzir produtos com qualidade superior, diferenciando o café commodity dos grãos de origem, definindo, assim, novos padróes de produtividade e de competitividade (ZYLBERSZTAJN; FARINA, 2001). Assim, a valorização do café brasileiro, considerandose o produto como uma bebida diferenciada e de qualidade, está crescendo à medida que o mercado consumidor começa a valorizar os cafés especiais. Os resultados encontrados demonstram uma dissonância entre a real qualidade do produto e a imagem da marca pois existem cafés brasileiros, vendidos para os consumidores locais, com alta qualidade, no entanto, o consumidor local não possui a imagem do produto associada com atributos de qualidade. Neste contexto, a criação de uma estratégia de construção de identidade da marca cafés do Brasil é importante, pois auxilia no desenvolvimento de novas associaçóes, o que poderá reeducar o consumidor brasileiro e aumentar a valorização do produto no país, desenvolvendo uma nova imagem (AAKER, 2007; BATEY, 2010). 
O estudo das atitudes concentra-se como um dos principais objetivos deste artigo, sendo assim, as atitudes da amostra foram medidas através das escalas: (1) Attitude toward the act - consuming a food item (SHIV; FEDORIKHIM, 1999); (2) Scale Name: Attitude toward the product, food (ARIAS-BOLZMANN; CHAKRABORTY; MOWEN, 2000). O resultado revela-se predominantemente positivo, mas também expóe que as atitudes positivas não são emocionais, colocando as atitudes utilitárias em destaque. Em contrapartida ao resultado exposto, Batey (2010) considera que as atitudes são componentes afetivos, em que o reconhecimento da importância dos elementos simbólicos, que revelam a natureza emocional da marca, é significativo para o entendimento da motivaçấo de compra dos consumidores. É cada vez mais fácil copiar atributos, benefícios e atitudes funcionais, do que fatores que influenciam diretamente a emoção das pessoas (BATEY, 2010).

A técnica de análise de clusters multivariada foi realizada a partir da escala atitudinal, na qual se revelaram três perfis comportamentais dos consumidores de café brasileiro. Com o intuito de aprofundar o estudo das atitudes, separam-se os consumidores em grupos, com o objetivo de reunir indivíduos a partir de comportamentos comuns. O Quadro 2 apresenta o resultado obtido pelas escalas da atitude segmentado em três diferentes clusters.

Quadro 2 - Média encontrada nas respostas separada por Clusters

\begin{tabular}{|c|c|c|c|}
\hline Variáveis & Cluster 1 & Cluster 2 & Cluster 3 \\
\hline Prejudicial/ Benéfico & 4,196 & 3,086 & 2,676 \\
\hline Não faz bem à saúde/ Faz bem à saúde & 4,215 & 3,172 & 3,054 \\
\hline Uma escolha tola/ Uma escolha sábia & 4,402 & 3,259 & 2,838 \\
\hline Inútil/ Útil & 4,589 & 3,569 & 3,189 \\
\hline Bom/ Ruim & 1,402 & 2,448 & 3,324 \\
\hline Prazeroso/ Não prazeroso & 1,271 & 2,069 & 3,865 \\
\hline Agradável/ Não agradável & 1,299 & 2,086 & 3,541 \\
\hline Satisfatório/ Não satisfatório & 1,252 & 2,190 & 3,378 \\
\hline Positivo/ Negativo & 1,458 & 2,172 & 3,432 \\
\hline Gosto bom/ Gosto ruim & 1,692 & 2,466 & 3,027 \\
\hline Excitante/ Tedioso & 1,776 & 2,517 & 2,973 \\
\hline Poderoso/ Fraco & 2,533 & 3,034 & 3,027 \\
\hline Caro/ Barato & 1,346 & 2,362 & 3,216 \\
\hline
\end{tabular}

Fonte: Elaborado pelas Autoras, 2015.

Cluster 1 - Brazilian Coffee Lovers: representam 53\% da amostra, possuem o maior nível de escolaridade entre os clusters, e são formados por uma maioria feminina. Dentro dos consumidores desse grupo, 83,17\% tomam café todo o dia, ou várias vezes ao dia, e podem ser considerados heavy users. No âmbito da verificação da origem do produto, $31,78 \%$ verificam sempre, e 33,64\%, às vezes, o que representa um envolvimento considerável 
com o produto. Conforme Blackwell, Miniard e Engel (2005), quanto mais importante o objeto, marca ou serviço para o consumidor, maior será seu grau de envolvimento. No caso desse primeiro cluster, o envolvimento é considerado alto devido ao nível de utilização, reconhecimento de atitudes emocionais e preocupação com a origem da bebida. Em relação às atitudes foi detectada maior tendência à predisposição positiva em relação aos cafés brasileiros, e maior atitude emocional. Os brazilian coffee lovers, como indica o nome, possuem maior conexáo emocional com o produto brasileiro, possuindo atitudes positivas, com as variáveis prazeroso, satisfatório e excitante. Esse grupo representa os consumidores que procuram cafés com maior qualidade, como os cafés especiais, por serem mais exigentes e possuírem maior vínculo afetivo com o produto.

Cluster 2 - Simpáticos aos cafés brasileiros: representam 29\% dos consumidores entrevistados, são formados por uma maioria feminina e apesar de ser o cluster que menos toma café, a maioria, 58,63\%, o consome todo o dia, ou várias vezes ao dia. Suas atitudes tendem a serem positivas, porém não totalmente emocionais. Os simpáticos demonstram possuir uma atitude em geral positiva, porém, a concordância com atitudes emocionais é mais fraca do que em comparação ao grupo dos Coffee Lovers. Apesar de não possuírem uma atitude emocional significativa, o cluster pode ser considerado simpático aos cafés brasileiros, pois são consumidores da bebida e tendem a possuir atitudes positivas em relação ao produto. Com a construção da marca Brasil de cafés, acredita-se que consumidores com o perfil desse grupo aumentariam a sua conexão emocional com a marca.

Cluster 3 - Distantes e Racionais: esse cluster representa apenas 18\% da amostra, é o agrupamento que mais possui pessoas do gênero feminino e o que mais possui consumidores com ensino superior incompleto. Entre os clusters apresentados, os Distantes e Racionais são os que possuem menos atitudes positivas aos cafés brasileiros. Todavia, é o segundo agrupamento que mais toma café, pois $70,27 \%$ dos consumidores tomam café todo o dia ou várias vezes ao dia. O grupo é considerado distante e racional perante os cafés brasileiros, porém, a grande maioria consome a bebida frequentemente. Pode-se associar esse agrupamento com o primeiro nível de envolvimento, indicado por Hawkins, Mothersbaugh e Best (2007). Esse nível corresponde ao da inércia, em que os consumidores não possuem motivação de compra significativa e o ato pode ser realizado por hábito.

Apesar de apenas um agrupamento demonstrar atitudes emocionais significativamente positivas em relação ao café brasileiro, este representa a maioria da amostra. Assim, nota-se que, apesar de o café ser considerado uma commodity, a evolução da exigência do consumidor em torno da qualidade está aumentando as associaçóes emocionais e sensoriais envolvendo o produto e o setor de alimentação como um todo, tornando cada vez mais necessária a construção de marca nessa categoria.

Neste artigo buscou-se analisar a atitude dos consumidores brasileiros envolvendo o consumo de cafés do Brasil. A importância deste estudo é devida à desvalorização do café brasileiro no mercado internacional em comparação com seus concorrentes. O Brasil é o maior exportador de café verde, commodity, e não do café industrializado, com maior valor agregado. A exportação de café industrializado encontra-se em dificuldade, principalmente devido ao protecionismo Europeu que visa garantir segurança e competitividade à indústria local que participa do processo de reexportação. Países como a Alemanha importam o grão 
verde brasileiro e o industrializam nacionalmente, diferenciando e adicionando marca ao produto, após, o exportam e o comercializam internamente.

Diante desses desafios, neste estudo centrou-se a análise nas atitudes dos consumidores brasileiros a fim de auxiliar a criação da marca Brasil de cafés de dentro para fora. Considerando-se o significativo protecionismo internacional, no que envolve cafés industrializados, a atitude positiva dos brasileiros perante o próprio café é de grande importância para a indústria local.

Através das duas etapas deste estudo pode-se concluir sobre algumas questóes que envolvem as atitudes e a imagem dos cafés brasileiros perante a amostra selecionada. Em primeiro lugar, nota-se que o café brasileiro não possui uma imagem e marca definidas na mente dos consumidores em questão, caracterizado, muitas vezes, como imagem confusa e inexistente. Essa percepção deve-se principalmente à falta de construção de marca dos cafés brasileiros. No âmbito da imagem analisada na etapa qualitativa, nota-se que até mesmo onde existe uma predisposição positiva em relação aos cafés especiais brasileiros, essa predisposição não está relacionada à lealdade para com o produto, ou com a certeza de que as atitudes positivas possuem como resultado a compra do objeto. Percebe-se, portanto, que os consumidores entrevistados reconhecem que os cafés brasileiros são de boa qualidade e possuem variedade, entretanto, a lealdade perante o produto é baixa ou inexistente. Uma marca apenas pode gerar valor e se diferenciar quando sua identidade se conecta com as percepçóes e sentimentos dos consumidores, construindo associaçóes fortes (AAKER; JOACHIMSTHALER, 2007; BATEY, 2010). Assim, os resultados deste estudo geram um alerta para a indústria do café sobre a estratégia em branding que, para criar de valor deve ser orientada para as necessidades e desejos dos consumidores. Assim, como desdobramento gerencial deste estudo fica a ideia de que as empresas do setor devem se focar mais na construção de marcas e no estabelecimento de valores que sejam percebidos pelos consumidores.

Compreende-se que as entrevistas realizadas na etapa qualitativa confirmaram a teoria de que a identidade construída pela marca deve estar diretamente em concordância com a imagem percebida pelos indivíduos. Para que a marca possua uma imagem adequada, a mesma deve, primordialmente, construir uma identidade (BATEY, 2010). Constata-se que a marca de cafés brasileiros não possui uma imagem concreta, pois a sua identidade é inexistente, havendo, portanto, uma ausência de estratégia de marketing no setor. Ou seja, existem diversas marcas brasileiras no ramo, as quais oferecem diferentes variedades e qualidades para um público variado, formando um posicionamento incerto para com os consumidores brasileiros.

No âmbito das crenças analisadas nas duas etapas deste estudo, destaca-se que os consumidores acreditam ser mais difícil encontrar cafés de boa qualidade do Brasil no próprio país do que no exterior. Sendo assim, apesar da crença de que a existência de cafés brasileiros de boa qualidade é positiva, os respondentes julgam que os melhores cafés nacionais são os destinados à exportação. Acredita-se que, assim como o exemplo do café colombiano (AGRAWALL; KAMAKURA, 1999), o Brasil possui o potencial de gerar associações positivas ligadas ao país de origem e à qualidade do grão através da criação de marca, considerando que é o maior produtor da espécie de grão de melhor qualidade 
Arábica, e produz cafés de alta qualidade e variedade. Considerando o desafio de entrada de cafés industrializados nos mercados internacionais, devido ao processo de reexportaçáo, propóe-se neste estudo o desenvolvimento da marca de cafés brasileiros de dentro para fora, gerando associaçóes positivas entre o país de origem e a qualidade da bebida. O efeito país de origem gera informaçôes importantes aos consumidores na hora da tomada de decisão, apresentando conotaçóes simbólicas e emocionais que influenciam os julgamentos das pessoas. Desta forma, a associação do Brasil como um produtor de grãos de qualidade deve ser desenvolvida através do conhecimento sobre as atitudes dos consumidores para a construção de uma estratégia de marca adequada. A identidade da marca deve estar relacionada com fatores emocionais ligados à cultura e ao ritual do café, e com atributos cognitivos associados ao padrão de qualidade dos grãos brasileiros. É a partir da construção e comunicação desta identidade que a imagem que os consumidores possuem sobre o café nacional irá ser aprimorada (AAKER; 2007; BATEY, 2010).

No que diz respeito aos aspectos hedônicos, apesar de existirem sentimentos associados ao ritual de tomar café e ao produto em si, os resultados náo demonstraram um alto nível de fatores emocionais ligados aos cafés brasileiros. Percebe-se, portanto, que os sentimentos estáo mais relacionados ao produto café e a outras marcas do que ao café nacional. Sendo assim, nota-se que nos aspectos positivos vinculados às atitudes, existe maior representatividade das reações cognitivas e, mais precisamente, das funçōes utilitárias das atitudes (AAKER; JOACHIMSTHALER, 2007). A racionalização cognitiva em questão deve ser modificada a partir da construção da marca no Brasil, desenvolvendo um processo de formação de identidade e melhoria da imagem "de dentro para fora". Ou seja, melhorar a imagem do café brasileiro no país, e, após, exportar essa imagem para o mundo.

A partir da escala aplicada ao bloco das atitudes, percebe-se que existem três diferentes públicos respondentes, separados em atitudes positivas, neutras e negativas em relação ao produto. O cluster 1 representa $53 \%$ da amostra, o cluster 2, 29\%, e o cluster 3, 18\%. Notase que a maioria dos consumidores apresenta atitudes consideradas positivas em relação aos cafés brasileiros. Entretanto, percebe-se que a maioria dos consumidores não possui atitudes formadas a partir da hierarquia experiencial, sendo que as atitudes utilitárias em torno do café, como as associadas a uma bebida agradável, sobressaíram em comparação às atitudes baseadas no consumo hedônico: prazer, excitação e poder. É interessante notar que, por mais que as atitudes se mostrem majoritariamente baseadas em informaçóes cognitivas, a satisfação e o prazer em torno do consumo de café revelam-se significativamente positivas, sobretudo no cluster 1 . Logo, os elementos cognitivos relacionados ao café e ao consumo da bebida são existentes e podem ser evidenciados a partir do processo de branding. Após a análise dos resultados obtidos apresentam-se, no próximo tópico, as consideraçóes finais.

\section{CONSIDERAÇÓES FINAIS}

Considerando o desafio de entrada de cafés nacionais industrializados nos mercados internacionais, esta pesquisa se propôs a compreender o consumo de cafés nacionais com base nos elementos formadores das atitudes dos brasileiros, com o intuito de propor a criação da marca de cafés do Brasil. Os resultados demonstraram que os consumidores, apesar de possuírem atitudes positivas perante o produto, estas são reaçôes em sua maioria 
cognitivas e não emocionais, demonstrando a necessidade da construção de marca. Destacam-se também que os consumidores acreditam ser mais difícil encontrar cafés de boa qualidade do Brasil no próprio país do que no exterior, além disso, o efeito halo se mostrou presente na imagem de cafés especiais brasileiros, pois, na medida em que existem fornecedores vendendo café com baixa qualidade no Brasil, os consumidores apreciadores de cafés especiais podem associar a baixa qualidade de um produto com todos os produtos da mesma origem.

As implicações gerenciais deste artigo concentram-se no conhecimento das crenças e atitudes positivas dos consumidores a respeito do café brasileiro, destacando-se a importância da desconstrução das crenças negativas, e a necessidade de aumento de atitudes emocionais através da construção de marca. Assim, acredita-se que as empresas podem utilizar os resultados desta pesquisa para fomentar a agregação de valor do café brasileiro, iniciando, assim, pelo conhecimento do consumidor interno. Para as empresas inseridas no sistema agroindustrial do café, o estudo das atitudes e crenças dos consumidores brasileiros auxilia na formulação da estratégia de marca dos cafés brasileiros, sendo que o conhecimento sobre o mercado-alvo consiste no primeiro passo para o desenvolvimento de valor. Assim, com a criação de marca cafés do Brasil é possível gerar associaçóes que conduzam os consumidores a associar a origem Brasil com grãos de qualidade, gerando um efeito país de origem positivo que influenciará nos julgamentos e atitudes sobre a marca.

Como sugestão para novos estudos, considera-se interessante a aplicação da pesquisa em mercados internacionais, sobretudo nos principais mercados consumidores do café brasileiro, como o Japão e os Estados Unidos, desenvolvendo a análise da diferença entre as atitudes dos consumidores internacionais e nacionais e explorando a imagem do café brasileiro também no exterior.

\section{REFERÊNCIAS}

AAKER, D. Construindo Marcas Fortes. Porto Alegre: Bookman, 2007.

AAKER, D; Joachimsthaler, E. Como construir marcas líderes. Porto Alegre: Bookman, 2007.

AAKER, D. Marcas Brand Equity: gerenciando o valor da marca. São Paulo: Negócio Editora, 1998.

AGRAWAL, Jagdish; KAMAKURA, Wagner A. Country of origin: A competitive advantage?. International Journal of Research in Marketing, v. 16, n. 4, p. 255-267, 1999.

ALBUQUERQUE, Elisabeth Maciel de. Avaliaçáo da técnica de amostragem

“Respondent-driven Sampling” na estimação de prevalências de Doenças Transmissíveis em populaçóes organizadas em redes complexas. Escola Nacional de Saúde Pública Sérgio Arouca - ENSP; Rio de Janeiro: Ministério da Saúde - Fiocruz, 2009. Dissertação de Mestrado, 99p. 
ALMEIDA, F. C. ; DROUVOT, H. O efeito do país de origem de produtos na percepção de executivos franceses e brasileiros. Gestão \& Regionalidade, v. 25, n. 73, p. 48-68, 2009.

ARIAS-BOLZMANN, Leopoldo; CHAKRABORTY, Goutam; MOWEN, John C. Effects of absurdity in advertising: The moderating role of product category attitude and the mediating role of cognitive responses. Journal of Advertising, v. 29, n. 1, p. 35-49, 2000.

ASSOCIAÇÃO BRASILEIRA DA INDÚSTRIA DE CAFÉ (ABIC). Portal ABIC. Disponível em: < www.abic.com.br>. Acesso em: 9 abr. 2015.

BATEY, MARK. O significado da marca: como as marcas ganham vida na mente dos consumidores. Rio de Janeiro: Best Business, 2010.

BARDIN, Laurence. Análise de conteúdo. Trad. Luís Antero Reto e Augusto Pinheiro. 3.ed. Portugal: Ed. 70, 2004.

BILKEY, W. 1. \& Ness, E. (1982). Country of Origin Effects on Product Evaluations. Journal of International Business Studies, Spring/Summer, p. 89-99.

BLACKWELL, Roger D. MINIARD, Paul W.; ENGEL, James F. Comportamento do Consumidor. Rio de Janeiro: Livros Técnicos e Científicos, 2005.

ENGEL, J. F.; BLACKWELL, R. E. e MINIARDI, P. W. Comportamento do consumidor. São Paulo: Pioneira Thomson Learning, 2005.

HAIR JR, Joseph F. et al. Fundamentos de métodos de pesquisa em administração. 2005.

HAWKINS, D; MOTHERSBAUGH L; BEST, R. Comportamento do consumidor: construindo a estratégia de marketing. Rio de Janeiro: Elsevier, 2007.

HAN, C. Min. Country image: halo or summary construct?. Journal of marketing research, v. 26, n. 2, p. 222, 1989.

INSCH, Gary S.; MCBRIDE, J. Brad. The impact of country-of-origin cues on consumer perceptions of product quality: A binational test of the decomposed country-of-origin construct. Journal of Business Research, v. 57, n. 3, p. 256-265, 2004.

VAN ITTERSUM, Koert; CANDEL, Math JJM; MEULENBERG, Matthew TG. The influence of the image of a product's region of origin on product evaluation. Journal of Business research, v. 56, n. 3, p. 215-226, 2003. 
VERLEGH, Peeter WJ; STEENKAMP, Jan-Benedict EM. A review and meta-analysis of country-of-origin research. Journal of economic psychology, v. 20, n. 5, p. 521-546, 1999.

KARSAKLIAN, Eliane. Comportamento do Consumidor. - 2 Ed., São Paulo, Atlas: 2000.

KELLER, Kevin. MACHADO, Marcos. Gestão estratégica de marcas. São Paulo: Pearson Prentic Hall, 2006.

LEÃO, E. de A.; PAULA, N. M. de. A produção de cafés especiais no Brasil e a emergência de novos padróes de competitividade. In: ENCONTRO REGIONAL DE ECONOMIA - ANPEC SUL, 13., 2010. Porto Alegre: UFRGS, 2010. p. 1-18.

LIMA, Manolita Correia. Monografia: A engenharia da produção acadêmica. 2 ed. São Paulo: Saraiva, 2008.

MATTAR, F. Pesquisa de Marketing: metodologia, planejamento. São Paulo: Atlas, 2005.

MARTINS, J. A Natureza Emocional da Marca: como escolher a imagem que fortalece a sua marca. São Paulo: Negócio. 1999.

MALHOTRA, Naresh K. Pesquisa de marketing: uma orientação aplicada. São Paulo: Prentice Hall: 2005.

MOWEN, I. C. MINOR, M. S. Comportamento do consumidor. São Paulo: Prentice Hall, 2003.

NEVES, Marcos. Marketing e Estratégia em Agronegócios e Alimentos. São Paulo: Atlas, 2011.

ORMOND, J; PAULA, S; CAFÉ FILHO, P.: (Re)conquista dos Mercados. Rio de Janeiro: BNDES setorial, 1999.

PAPADOPOULOS, Nicolas et al. Effects of subcultural differences on country and product evaluations. Journal of Consumer Behaviour, v. 2, n. 3, p. 232-247, 2003.

PETER, J. Paul; OLSON, Jerry C. Comportamento do Consumidor e Estratégia de Marketing. 8. ed.. São Paulo: Editora McGraw-Hill, 2009.

SHIMP, Terence A.; SAMIEE, Saeed; MADDEN, Thomas J. Countries and their products: a cognitive structure perspective. Journal of the Academy of Marketing Science, v. 21, n. 4, p. 323-330, 1993. 
SOLOMON, Michael R. O comportamento do consumidor: comprando, possuindo e sendo. Porto Alegre: Bookman, 2002.

SCHIFFMAN, Leon G.; KANUK, Leslie Lazar. Comportamento do consumidor. 9.ed. Rio de Janeiro: LTC, 2009.

TAVARES, Mauro Calixta. Gestáo de marcas: construindo marcas de valor. São Paulo: Harbra, 2008.

ZILBERSZTAJN, Décio; et al. O sistema agroindustrial do café: um estudo da organizaçáo do agribusiness do café visto como a chave da competitividade. Porto Alegre: Ortiz, 1993.

ZYLBERSZTAJN, D.; FARINA, EMMQ. Projeto: diagnóstico sobre o sistema agroindustrial de cafés especiais e qualidade superior do estado de Minas Gerais. São Paulo: Pensa/Sebrae, 2001. 